\title{
Geographic variation in sexual selection and implications for speciation in the Barn Swallow
}

\author{
Elizabeth SC Scordato ${ }^{*}$ and Rebecca J Safran
}

\begin{abstract}
Barn Swallows (Hirundo rustica), a group of passerine birds comprised of six closely related subspecies, are well known throughout their nearly worldwide distribution, in part because of their close association with human settlements. A tractable species for both individual-based and population-level studies, Barn Swallows are a prominent model system in evolutionary, ecological, and behavioral research. Here we review work on sexual selection and population divergence in this species complex, focusing on comparative studies among populations and subspecies. We summarize variation in the targets of mate choice and in the information conveyed by sexually selected traits, and conclude that the benefits advertised by different traits may vary geographically. Finally, we consider the role of sexual selection as a driver of population divergence in this widespread and phenotypically variable species complex.
\end{abstract}

Keywords: Barn Swallow, Geographic variation, Natural selection, Sexual selection, Speciation, Tail streamers, Ventral color

\section{Introduction}

A spring and summer inhabitant of the Holarctic, the Barn Swallow (Hirundo rustica) is the most widespread species of the swallow family, Hirundinidae. The extensive breeding range of the Barn Swallow is believed to be due in part to their close association with human populations. Based on patterns of human colonization in Eurasia and recent phylogenetic studies in swallows, it appears that this association with humans has persisted for millennia (Zink et al. 2006). Indeed, swallows will nest nearly everywhere there are barns or bridges, especially if these are situated near water and fields. In addition to human structures providing nest sites, swallows benefit from agriculture: the insects surrounding livestock are an excellent food source for these aerial insectivores. The Barn Swallow is thus well known and easily recognizable throughout rural areas worldwide, and has been the subject of extensive behavioral, ecological, and evolutionary research since the early part of the 20th century (reviewed in Møller 1994a; Turner 2006).

Barn Swallows are divided into six subspecies (del Hoyo and Elliott 2014, Figure 1). The nominate form, H. $r$. rustica, breeds throughout Europe, North Africa, and

\footnotetext{
* Correspondence: elizabeth.scordato@colorado.edu

Department of Ecology and Evolutionary Biology, The University of Colorado, Boulder, CO 80309, USA
}

(c) 2014 Scordato and Safran; licensee BioMed Central. This is an Open Access article distributed under the terms of the Creative Commons Attribution License (http://creativecommons.org/licenses/by/4.0), which permits unrestricted use, distribution, and reproduction in any medium, provided the original work is properly credited. The Creative Commons Public Domain Dedication waiver (http://creativecommons.org/publicdomain/zero/1.0/) applies to the data made available in this article, unless otherwise stated. sub-Saharan Africa in the winter. Further east in Russia, H. r. tytleri occurs in the Baikal region and south into Mongolia, and is believed to overwinter in India and Southeast Asia. The phenotypically variable $H$. r. gutturalis overwinters in Southeast Asia and breeds in the Russian Far East, China, Japan, and Korea (although it has sometimes been divided into as many as four different subspecies throughout this range, del Hoyo and Elliott 2014). Two subspecies with comparatively restricted ranges also occur in the Middle East and North Africa: $H$. r. savignii is a year-round resident in the Nile Valley in Egypt, and $H$. $r$. transitiva is a short-distance migrant breeding in Israel, Jordan, Lebanon, and Syria. A single subspecies, H. r. erythrogaster, occurs throughout North America and overwinters in Central and South America. A breeding population has also recently established itself in Argentina (Martínez 1983).

There is extensive phenotypic variation among these six subspecies, particularly in body size, the length of the "tail streamers" (the outermost tail feathers), and ventral color, which ranges from nearly pure white in some populations to a dark rusty orange in others (Figure 2, reviewed in del Hoyo and Elliott 2014). These latter two traits have been the subject of sexual selection research in several populations. Males of the European $H$. r. rustica are on 


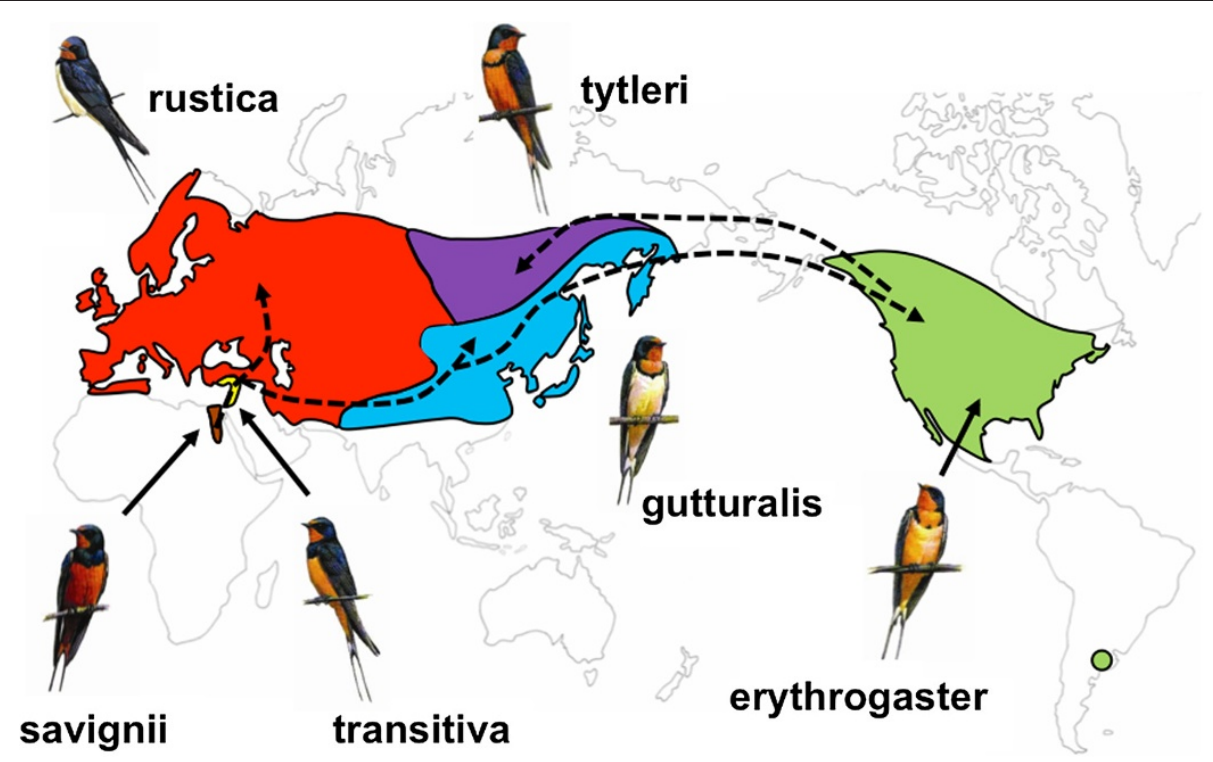

Figure 1 Range map of the six barn swallow (Hirundo rustica) subspecies. Dashed arrows show hypothesized directions of colonization from an African common ancestor. Note the back-colonization of the Baikal region by North American swallows, which eventually gave rise to H. r. tytleri. Figure adapted from Dor et al. (2010).

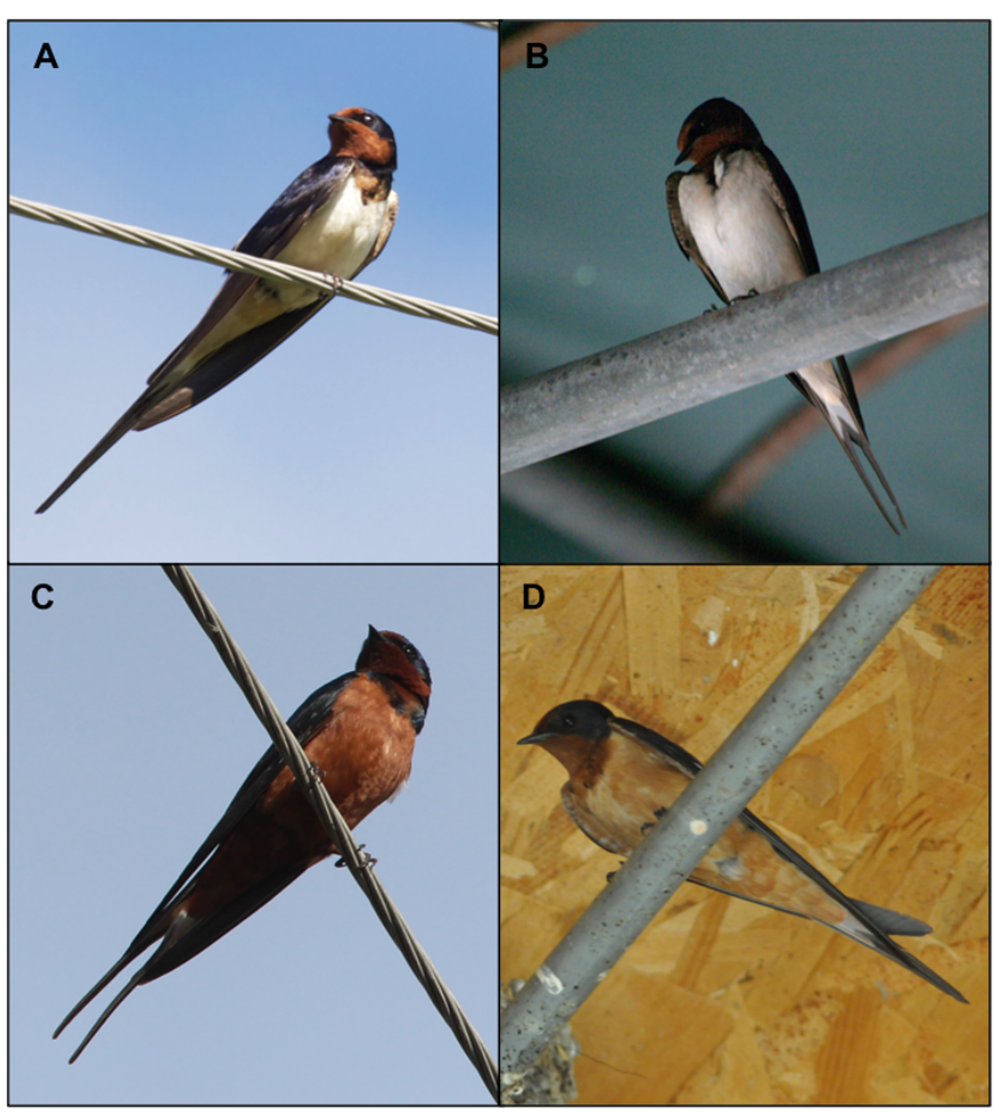

Figure 2 Four of the six barn swallow subspecies. A) nominate European H. r. rustica, with pale ventral coloration and long tail streamers B) East Asian H. r. gutturalis, with pale ventral coloration and short streamers; C) Baikal region H. r. tytleri with very dark ventral coloration and intermediate streamers; and D) North American H. r. erythrogaster with dark ventral color and short streamers. Note that tytleri is much more similar in coloration to erythrogaster than to the geographically proximate Eurasian subspecies, supporting phylogenetic data that suggest it has re-colonized Asia from a North American ancestor. Photos courtesy of M. Wilkins. 
average largest in body size, palest in ventral color and have the longest tail streamers of all of the subspecies (Møller 1994a, Safran et al. in review). The North American populations are on average much darker in ventral color, with tail streamers tending to be intermediate in length to other subspecies (Safran et al. in review). Populations of the two sedentary subspecies $(H$. r. savignii in Egypt and H. r. transitiva in the Middle East) have relatively large body size, dark plumage coloration, and long streamers (although $H$. r. savignii is darker and shorterstreamered than H. r. transitiva, (Vortman et al. 2013)). H. r. tytleri, in the Baikal region, is of intermediate body size and exhibits intermediate streamer lengths with dark ventral color, while East Asian H. r. gutturalis has very small body size, pale orange-brown ventral color, and the shortest tail streamers of all subspecies. Despite these broad phenotypic differences, there is latitudinal variation within subspecies and some overlap in some trait values between subspecies (Møller 1994a). Within subspecies, there is sexual dimorphism in both streamer length and ventral color, although variation in female phenotype among subspecies mirrors male variation to some extent (Møller 1994a, del Hoyo and Elliott 2014).

Phylogenetic reconstructions of the species complex indicate an African common ancestor, of which the Middle Eastern H. r. savignii and $H$. r. transitiva are likely the closest relatives (Figure 3, Zink et al. 2006; Dor et al. 2010). Barn swallows then expanded their range throughout Eurasia, with $H . r$. rustica and $H$. $r$. gutturalis likely diverging a via vicariance events (Zink et al. 2006). Birds from the Asian populations also crossed the Bering Strait to populate North America an estimated 100000 years ago, giving rise to the $H$. $r$. erythrogaster subspecies. Most interestingly, these North American swallows apparently re-crossed the Bering Strait and recolonized the Baikal region, as mtDNA indicates that $H . r$. tytleri is nested within the erythrogaster clade, and these two subspecies are much more phenotypically similar than $H$. r. tytleri is to the more geographically proximate rustica or gutturalis
(Figure 2). This range expansion and concomitant phenotypic differentiation among the six subspecies has occurred on a rapid evolutionary timescale (estimates are approximately 100000 years ago for the Asian-North America split and 27000 years ago for the North AmericaBaikal dispersal event, Zink et al. 2006). Indeed, divergence is not complete, as hybridization and gene flow occur at most subspecies borders (Turner 2006; Dor et al. 2012). The patterns of phenotypic differentiation among subspecies, coupled with recent divergence and ongoing gene flow, have made the Barn Swallow system one of particular interest in the fields of sexual selection and speciation, which are the focus of this review.

The first studies of sexual selection in Barn Swallows were conducted in European populations of H. r. rustica, and focused primarily on the role of tail streamer length in mate choice. However, when research began on North American H. r. erythrogaster in the 1990s, it became apparent that streamer length played a different role in reproductive success in this subspecies than it did in Europe, although sample sizes for these studies were small (Smith and Montgomerie 1991; Smith et al. 1991). Geographic variation in the targets of mate choice has subsequently drawn attention to the role that sexual selection may play in population divergence and speciation in the Barn Swallow complex. Here, we first review what is known about the evolution and social function of streamer length and ventral coloration in different subspecies of Barn Swallow; these two traits have been the subject of the most extensive research. We also consider the role of song in sexual selection, which is less well studied than color and streamer length but nonetheless seems to play a role in both male competition and mate choice. We summarize data related to sexual selection on these traits in the different subspecies, and then consider the role of geographic variation in sexual selection pressures in population divergence and speciation. We do not discuss traits that have been studied in only a single subspecies of Barn Swallows (e.g., nest size, asymmetry, senescence),

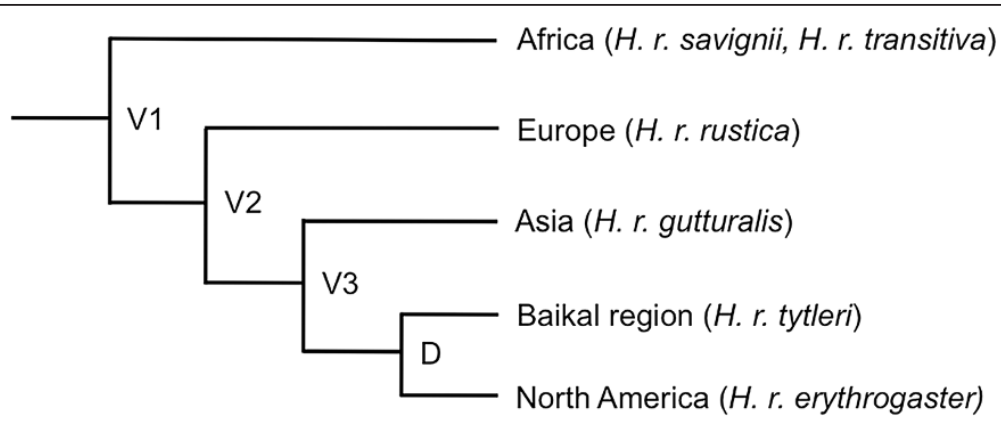

Figure 3 Major clades within the barn swallow complex. The splits between African and Europe (V1), Europe and Asia (V2), and Asia and North America (V3) likely arose via vicariance events, whereas the split between North America and the Baikal region (D) is likely due to dispersal of North American birds into Eastern Russia. Figure modified from Zink et al. (2006). 
as there is no comparative data available. We conclude by highlighting future directions for ecological and evolutionary research on this species complex.

\section{Review \\ Sexually selected traits in the Barn Swallow}

Sexual selection was originally conceived by Darwin (1871) to explain the widespread presence in nature of elaborate and conspicuous traits that do not contribute to an organism's survival, and indeed often seem detrimental to its fitness. Darwin postulated that these traits evolve because they are attractive to members of the opposite sex and/or aid in competition for mates; hence, costly and elaborate traits could persist because they enhanced an individual's mating success, if not its survival. A sexually selected trait is therefore defined as any trait that assists an individual in the acquisition of mates or fertilizations (Andersson 1994). These traits can evolve via female choice (i.e., females mate with males that display the most elaborate traits), or by male-male competition (i.e., males with the most elaborate traits are best able to monopolize access to fertile females). Both cases result in directional selection on traits because males with the most elaborate sexually selected traits are often those that enjoy the greatest reproductive fitness.

A central question in sexual selection research is why females prefer males that display showy and presumably costly traits. The most common explanation is that elaborate male traits advertise benefits a female may obtain by mating with that male. These benefits fall into two categories: direct benefits which affect female fitness, such as a male's ability to provide resources, good paternal care or high quality territories to his mate (Price et al. 1993; Kirkpatrick 1996); and indirect, or genetic benefits, which advertise a male's ability to produce attractive, healthy, or high-quality offspring (Iwasa et al. 1991; Kirkpatrick 1996). Both types of benefits models rely on sexual signals being "honest indicators" of male quality (Zahavi 1975); that is, only the highest quality males have the surplus resources available to bear the costs associated with developing and maintaining elaborate traits (Grafen 1990). More elaborate signals therefore advertise higher quality males who can provide better benefits, and females should choose to mate with males that exhibit the most elaborate version of the preferred trait (Grafen 1990). A major focus of sexual selection studies is thus identifying the costs and benefits (both direct and indirect) associated with putative sexually selected traits.

Determining whether or not a trait is sexually selected requires extensive empirical work. Although it is often tempting to assume that any elaborate or sexually dimorphic trait (e.g., bright colors, ornamental feathers, or weapons) is sexually selected, these traits can also evolve for other purposes, such as mimicry, aposematic signaling, and species recognition (e.g., Jiggins et al. 2004; Maan and Cummings 2008; Price 2008). To show that a trait is subject to sexual selection, a causal relationship between trait variation and reproductive success must be demonstrated. The best way to do this is using field experiments that manipulate a trait to be more or less exaggerated than average and then measuring the effects of this manipulation on some aspect of fitness, such as timing of breeding, pairing success, or number of offspring. Barn Swallows are a favored model system in sexual selection studies, as their most obvious sexually selected traits, tail streamers and color, are both relatively easy to manipulate (e.g., tail streamers: Møller 1988, 1989; color: Safran et al. 2005). Substantial work has thus been devoted to identifying the costs and benefits advertised by these traits.

\section{Tail streamers in European H. r. rustica}

The best studied of the Barn Swallow's sexually selected traits are the tail streamers. Since this trait is strongly sexually dimorphic in European populations, scientists studying $H$. $r$. rustica quickly suspected that these traits were under sexual selection in males. To determine whether there is a relationship between tail streamer length and male mating success, Møller (1988) artificially elongated and shortened streamer length and examined whether this affected a male's ability to attract a mate. Males with artificially elongated tail streamers mated earlier than their shortstreamered neighbors - the first demonstration of a causal relationship between male tail length and female mate choice in Barn Swallows. Indeed, since that initial study and the dozens that have followed (reviewed in Møller et al. 1998a; Turner 2006), tail streamers in European $H$. r. rustica have become a textbook example of sexual selection. Further experimental and correlational studies confirmed that females prefer males with the longest tail streamers: long-tailed males produce the most offspring (in their first clutches and total number of young per season) each year because they pair and breed earlier and successfully fledge more broods than shorter-tailed males (reviewed in Møller 1994a; Møller et al. 1998a). Naturally long-streamered males likely breed earlier because they are in better condition and arrive on the breeding grounds earlier than shorter-streamered males (Møller 1994a; Møller et al. 2003; Ninni et al. 2004), which gives them an advantage for obtaining high quality nest sites and mates, as well as producing more broods.

Barn Swallows are socially monogamous and exhibit biparental care (Møller 1994a). However, they also pursue extra-pair matings. This means that in any given nest, some offspring are likely not genetically related to the male caring for them, and counting the number of chicks in a nest is thus not necessarily an accurate reflection of the male nest owner's reproductive output. Molecular parentage analyses provide a definitive measure of a male's 
reproductive success, and allow a more accurate assessment of the strength of sexual selection associated with different traits. In European populations of Barn Swallows, the proportion of extra-pair young (EPY) in a nest averages 17.8-34\% (Saino et al. 1997b; Møller et al. 1998b). Møller's (1988) tail manipulation study was replicated in Europe and confirmed that males with the longest streamers obtained a significantly greater share of genetic paternity in their nests and in the nests of others, relative to their short-streamered neighbors (Møller and Tegelström 1997; Saino et al. 1997b).

Tail streamers are a particularly interesting sexually selected trait because they have a clear function unrelated to mating. As aerial insectivores, Barn Swallows must fly efficiently, a task that is substantially aided (or hindered) by the shape of their tails. Thus, rather than evolving under directional sexual selection alone (as would be predicted if the longest-streamered males always had the highest fitness), this trait is predicted to be shaped by a balance between sexual and natural (viability) selection. This appears to be borne out by empirical data: individuals with longer streamers suffer from impaired aerodynamic performance that may result in lower foraging efficiency (Møller et al. 1998a; Bro-Jørgensen et al. 2007), and population-level survival is lower when male streamer length is longer on average (Møller and de Lope 1994). There is some evidence that high condition males with naturally longer tails have higher survival (Møller 1991a; Møller 1994a), although more recent mark-recapture analyses of annual population means shows that males with naturally longer tails have lower survival (Møller and Szép 2002). Swallows with too short a set of streamers also suffer from reduced flight skills (Buchanan and Evans 2000; Rowe et al. 2001). The balance between tail feathers that are too long or too short implies that there is a naturallyselected optima for tail length, and that sexual selection may drive tail length away from this optima (Møller et al. 1995; Evans and Thomas 1997; Buchanan and Evans 2000; Bro-Jørgensen et al. 2007).

The apparent costs associated with elongated tail streamers led researchers to hypothesize that tail length is an honest signal of male quality: only high condition males can bear the costs of elongated tails. If this is true, females should gain benefits from mating with longer-tailed males, which leads to directional sexual selection on streamer length that will ultimately be opposed by viability selection when the survival costs of long tails outweigh the benefits from increased mating success. There is some evidence for the type of "quality" that long-tailed males might be signaling: European males with longer tails had fewer ectoparasites (Saino and Møller 1994) and more robust immune responses (Saino et al. 1997a, 2002), suggesting that tail length advertises information about immune system quality. Experimental data manipulating tail length also found that long-tailed males were better able to cope with the immune costs of their elaborate traits (Saino and Møller 1996). Some aspects of the immune response appear to be heritable, as a positive correlation was found between ectoparasite loads on fathers and sons (Møller 1990; Møller et al. 2004), meaning that females paired to longtailed males may gain indirect benefits in the form of healthy sons. Females may gain direct benefits from mating with healthy, long-tailed males as well, via less exposure to contagious ectoparasites.

Long tails seem to advertise additional qualities besides immune function: males with longer tails had higher levels of circulating testosterone, which may be related to competitive ability (Saino and Møller 1994), and the sons of long-tailed males had greater longevity than those of short-tailed males (Møller 1994b), which could be due to good genes, better parental care in nests with long-tailed fathers, or other heritable components of longevity. These latter effects are difficult to partition, particularly because long-tailed males obtained high-quality females as mates (Møller 1991b), high quality females also had long tails (Møller 1991b; Cuervo et al. 1996b), and females mated to attractive, long-tailed males invested more in reproductive effort (de Lope and Møller 1993). Thus, some of the benefits experienced by the offspring of long-tailed males are likely due to their high-quality mothers, although offspring may also suffer due to reduced investment from their long-tailed fathers (de Lope and Møller 1993). Taken together, long tail streamers seem to be indicators primarily of indirect benefits: females mated to long-streamered males do not obtain better paternal care (indeed, elevated testosterone and longer tails resulted in poorer parental care, de Lope and Møller 1993; Saino and Møller 1995a), but they produce healthy, long-lived offspring and longstreamered sons.

However, another hypothesis suggests that tail streamer length is not an honest signal of a male's ability to withstand a "too long" streamer, but rather is optimized to individual-specific flight performance and thus subject to natural selection (Cuervo et al. 1996a; Evans and Thomas 1997; Buchanan and Evans 2000). To differentiate these alternatives, Bro-Jørgensen et al. (2007) utilized an individual-based approach to study flight performance as a function of streamer length. They analyzed aerodynamic performance after manipulating tail streamers to multiple different lengths, and found no evidence to support the view that the sexually selected component of this trait reflects individual variation in flight performance. Instead, the optimal streamer length for efficient flight varied among males, but beyond a certain point, any additional length to the streamer, presumably caused by sexual selection, did not vary among individuals. The conclusion is that the naturally, rather than the sexually, selected component of the streamer conveys information 
about a male's flight and foraging performance, leaving open the question of why streamers are elongated past this optimal value. Bro-Jørgensen et al. (2007) speculate that tail streamer lengths may simply serve to signal the age and sex of the individual (adult male vs. female or juvenile), and indeed, older males typically have longer tails, although the benefits associated with streamer length are still found when controlling for the effect of age (Møller et al. 1998a). The relative roles of natural and sexual selection in shaping elongated tail streamers thus remain debated (e.g., Evans 1998, 1999; Hedenström and Møller 1999; Evans 2004; Evans et al. 2012; Aparicio and Møller 2012), particularly because an explicit link between flight performance and fitness has not been demonstrated. Further experimental studies that adopt a within-individual experimental approach with additional treatments related to mate-selection may provide a definitive test for understanding the relative contributions of sexual and natural selection to variation in streamer length.

\section{Geographical variation in sexual selection on tail streamers}

All of the above studies were conducted in European populations of $H$. r. rustica. However, there are five other Barn Swallow subspecies, and there is mounting evidence that the function of tail streamers is not the same in all groups. This may to some extent be predicted by variation in streamer length among subspecies: for example, despite some latitudinal variation, tail streamers are on average shorter in North American than European populations, and the extent of sexual dimorphism in streamer length is much reduced (Safran and McGraw 2004). This leads to the a priori suggestion that this trait may be subject to weaker sexual selection in North America compared to Europe.

Available correlational and experimental data generally bear out this prediction. For example, in contrast to European $H$. r. rustica, streamer variation in males and females did not significantly predict patterns of assortative pairing in North American H. r. erythrogaster (Safran and McGraw 2004). Male streamer length was not a significant predictor of measures of seasonal reproductive success in some correlational data sets (Safran and McGraw 2004; Neuman et al. 2007), but in a Canadian population males with naturally long streamers bred earlier (Smith and Montgomerie 1991) and had increased extra-pair mating success compared to shorter-streamered males (Kleven et al. 2006). In the same Canadian population, a positive correlation was found between streamer length and fertilization success, but much of this relationship was explained by the age-dependence of streamer length: older males had both greater fertilization success and longer streamers, making it difficult to separate these effects on reproductive success (Lifjeld et al. 2011).
Additional components of reproductive success vary with respect to streamer length between European and North American populations. In Europe, there is a significant positive association between streamer length and the proportion of offspring sired in first breeding attempts (Saino et al. 1997b), whereas no such significant association was found between these two variables using the same test statistic in North American population (Neuman et al. 2007). Likewise, males with longer tails sired more offspring in their own nests in Europe (Saino et al. 1997b) but the relationship was not significant in North America (Neuman et al. 2007). A negative correlation was found between the proportion of broods being sired by extra-pair males and the streamer length of the male nest owner in a population in Denmark (Møller and Tegelström 1997), indicating that longer-tailed males are less likely to be cuckolded, but no such correspondence between a male's streamer length and his probability of being cuckolded was found in New York with the same test statistic (Neuman et al. 2007). Finally, a study that replicated the experimental design of Møller's (1988) tail manipulation study in Europe did not find a significant effect of artificial streamer elongation on male reproductive success in a North American population of swallows (Safran et al. in review).

Despite latitudinal variation in streamer lengths within Europe, the function of streamers, in terms benefits related to social and genetic reproductive success, vary little among European populations of H. r. rustica (Møller 1995). By contrast, male H. r. erythrogaster with elongated streamers in New York did not obtain the same reproductive benefits as males with elongated streamers in Italy (see above). Considered in concert, the results of studies in North America and Europe demonstrate that the pattern of sexual selection on tail streamers varies among subspecies.

Two other Barn Swallow subspecies have been the subjects of additional sexual selection studies: $H$. r. transitiva in Israel, and H. r. gutturalis in Japan. Again, there appears to be variation in sexual selection on tail streamers among these subspecies. Male $H . r$. transitiva have tail streamers that are nearly as long as those in $H$. r. rustica, and, accordingly, males with longer streamers breed earlier and have fewer extra pair young in their nests in both correlational (Vortman et al. 2011) and experimental (Vortman et al. 2013) studies. By contrast, male $H$. r. gutturalis, which have much shorter streamers than $H$. r. rustica and H. r. transitiva, do not gain any significant reproductive benefits based on tail length in correlational datasets (Kojima et al. 2009; Hasegawa et al. 2010).

\section{Ventral coloration in North America}

Although North American swallows have shorter tail streamers than their European counterparts, they have 
much darker ventral coloration. Accordingly, ventral coloration, not streamer length, was found to correlate with patterns of pairing and seasonal reproductive success in two populations of North American Barn Swallows (Safran and McGraw 2004; Neuman et al. 2007; Eikenaar et al. 2011a), but not in another (Lifjeld et al. 2011), suggesting that darker coloration may be a target of mate choice in some H. r. erythrogaster populations. Experimental manipulations of male coloration further demonstrated that females use ventral color to assess male quality. In North American populations, males with experimentally darkened ventral color gained greater paternity relative to the amount obtained in their first breeding attempts, prior to the color manipulation (Safran et al. 2005), but experimentally elongated tail streamers did not predict increased paternity allocation; in fact, males with reduced streamer lengths actually obtained greater paternity (Safran et al. in review).

It is unclear why females favor the use of color for mate selection in some populations and streamer length in others. Feather color in Barn Swallows is not as obvious a "costly signal" as elongated streamers, as darker ventral color probably doesn't hinder foraging ability, and darker birds are unlikely to be more conspicuous to predators (as is the case for some costly, bright-colored signals). There is evidence in other systems that bright red and orange carotenoid-based colors are costly and/or honest signals, because carotenoid pigments must be obtained from the diet and physiologically modified before deposition in tissues (reviewed in Hill and McGraw 2006). However, the orange-brown throat and ventral color in Barn Swallows is caused by eu- and phaeomelanin pigments rather than carotenoids, which can be synthesized endogenously (McGraw et al. 2005) and are not generally believed to be costly to produce (Hubbard et al. 2010). However, recent studies have revealed that there may indeed be costs to deposition of melanin pigments. In addition to stimulating melanogenesis in external tissue, the melanocortin pathway serves non-signaling functions such as regulation of stress and immune responses via binding of peptide derivatives to different melanocortin receptors (Ducrest et al. 2008). Allocation of melanocortins to different receptors may result in a tradeoff between pigment deposition and hormonal function (e.g. Roulin et al. 2008). Melanin-based signals can also be sensitive to oxidative stress (Galván and Alonso-Alvarez 2008, 2009), and thus have the potential to function as an honest signal of antioxidant levels.

Several recent studies have illuminated some of the physiological mechanisms underlying color variation, and shed light on the type of information that darker males may be signaling to prospective mates and competitors. Dark melanin pigmentation appears to be linked to hormonal state: in North American populations, artificially darkened females adjusted their physiological state to have lower levels of testosterone and reactive oxidative metabolites than prior to manipulation (Vitousek et al. 2013). Likewise, naturally darker males were found to have higher levels of circulating testosterone, and experimentally darkening an individual's color increased his testosterone levels (Safran et al. 2008). These experimental findings demonstrate feedbacks between external phenotype and physiological state: experimentally darkened birds likely had different types of social interactions than when they had lighter feathers, resulting in an adjustment of hormonal state to match their new phenotype.

It may be beneficial for naturally dark-colored males to advertise their high levels of testosterone. If these dark, high-testosterone males are more aggressive, they could be more competitive in obtaining high quality nesting territories early in the breeding season (Safran et al. 2008), making them more attractive to females. Indeed, females paired to darker males increased feeding rates of their chicks, although dark males themselves did not give more paternal care than lighter males (Maguire and Safran 2010). This finding suggests that females invest more in their offspring when paired to attractive mates. If darker males can obtain and defend better nest sites, this represents a direct benefit to their mates; however, there is also a potential cost in that high-testosterone males tend to be poorer parents in both Barn Swallows and other bird species (e.g., Ketterson et al. 1992; Saino and Møller 1995a, but see Eikenaar et al. 2011b). In both Europe and North America, therefore, there is evidence that the main target of female choice (tail length and ventral color, respectively) is linked to high levels of circulating testosterone and may advertise a male's competitive ability. Dark coloration in North America is also heritable to some extent (Hubbard et al. in review), suggesting that females paired to dark colored males may obtain indirect benefits in the form of attractive offspring.

\section{Plumage coloration in other populations}

Darker ventral color is also associated with greater breeding success in Middle Eastern swallows (H. r. transitiva), a subspecies that exhibits elongated tail streamers and dark ventral color. Experimental work in this subspecies has shown that both ventral color and tail streamer length predict different aspects of breeding success, with darker males raising more young over the course of a season, and males with longer tail streamers breeding earlier and having fewer extra-pair chicks in their nests (Vortman et al. 2011, 2013).

Ventral color needn't be the only target of sexual selection on plumage- indeed, in a subspecies with pale ventral coloration, it appears that the size of the dark orangebrown throat patch is the trait most preferred by females. In a Japanese population of $H$. r. gutturalis, females preferred males with larger throat patches, and, accordingly, 
the throat patch is on average twice as large in $H$. r. gutturalis as in the closely related $H$. r. rustica (Hasegawa et al. 2010; Hasegawa and Arai 2013a). Males with larger, darker throat patches obtained high-quality females who initiated clutches earlier than females paired to lighter males (Hasegawa et al. 2010, Hasegawa and Arai 2013b). Darker-throated males also had greater survival probability (Hasegawa et al. 2013), and obtained higher quality territories and reduced their paternal care (Hasegawa et al. 2014), relative to small- and pale-throated males. Male tail streamer length was linked to survival rate but unrelated to measures of reproductive success (Kojima et al. 2009; Hasegawa et al. 2010), consistent with the relatively short length of male streamers in this population.

Studies of melanin-based coloration in European populations of Barn Swallows have thus far focused primarily on the potential for melanic signals to advertise information about viability, immunocompetence, and stress. These populations have paler ventral coloration in comparison to males in other subspecies (e.g., H. r. gutturalis, H. r. transitiva, and $H$. r. erythrogaster), and studies show that paler males have higher survival between years (Saino et al. 2013b). Moreover, naturally paler birds have a stronger primary immune response, but not cell-mediated immune response (Saino et al. 2013a), suggesting a possible immune cost to darker ventral plumage in this population. If darker coloration is associated with poorer immune response, this may be an important source of "honesty" in melanin-based signals. Interestingly, although birds with darker ventral color have a weaker immune response, individuals with darker throat color have higher survival in a Danish population (Galván and Møller 2013), similar to Japanese H. $r$. gutturalis (Hasegawa et al. 2013). Melanic throat color is heritable in Italian populations (Saino et al. 2013c), suggesting that different color patches could advertise different information.

There may also be a relationship between the stress hormone corticosterone and coloration, but this only emerged in experimentally stress-reduced males in Europe (i.e., among males with artificially reduced brood sizes, paler males had less corticosterone and may thus have been less stressed, Saino et al. 2013a). Moreover, a North American study of melanin color in males (both nestlings and adults) found no correlation between color and different measures of corticosterone (Jenkins et al. 2013). The relationship between stress and melanin-based color thus remains unclear. Some of the complication in interpreting the costs of melanin production and deposition comes from the different physiological pathways associated with producing eu- vs. phaeomelanin (Saino et al. 2013a, b), which remain poorly understood in most natural populations. Additionally, feathers are a static signal that likely reflect the hormonal state of the individual when the feathers were grown; thus, measuring hormones months after the trait has developed may not provide useful information about the costs or benefits being signaled. Further research on the relative signaling roles of the two different melanin pigments, as well as on temporal variation in hormone responses, will help elucidate the role of melanin-based ornaments in sexual selection.

Additional plumage characters that have been the focus of some research are the white spots on the underside of the tail feathers. These are sexually dimorphic, and area of white spots is significantly correlated with streamer length. In European populations, males with experimentally reduced white spot sizes fledged fewer offspring, likely because they were less likely to have second broods (Kose and Møller 1999). The white portions of the feather are more prone to breakage (Kose and Møller 1999) and are also the preferred feeding sites of feather lice, although males with larger white spots have fewer lice (Kose et al. 1999). This suggests white spots could signal ectoparasite infestations (Kose et al. 1999). In Japanese H. r. gutturalis, males with larger white tail spots bred earlier in the season, suggesting this trait may be sexually selected in these populations as well (Hasegawa et al. 2010).

\section{Song in mate choice and male competition}

Though not nearly as well studied as streamer length and ventral color, some work has been done on the social function of Barn Swallow song, primarily in European populations of H. r. rustica. Unlike color and morphology, song is learned and culturally inherited. It is also a dynamic signal, capable of changing with season, social context, and physiological state. It thus stands to reason that song may advertise different information than comparatively static signals like color or streamer length. However, interpreting song variation can be difficult, particularly in Barn Swallows, in which males sing enormously complex and variable songs and have relatively large repertoires of unique syllables (Figure 4, Galeotti et al. 1997). This creates problems for researchers both in determining which song variables to measure and in correcting for large numbers of comparisons. Studies of song variation typically examine a variety of parameters related to song structure (e.g., number of syllables, length of syllables, number of syllable types, total repertoire size) and acoustic characteristics (e.g., peak, maximum, and minimum frequencies of different song components). Additionally, song rate (the number of songs produced per unit of time) is often measured independently of song structure. One feature of Barn Swallow song that has received particular attention is the "rattle", a harsh trill appended to the end of most songs that varies in length among males (Figure 4).

Studies of European Barn Swallow song suggest that different song features serve different functions and advertise different information. For example, males with more neighbors produced longer rattles, and shorter, less complex 


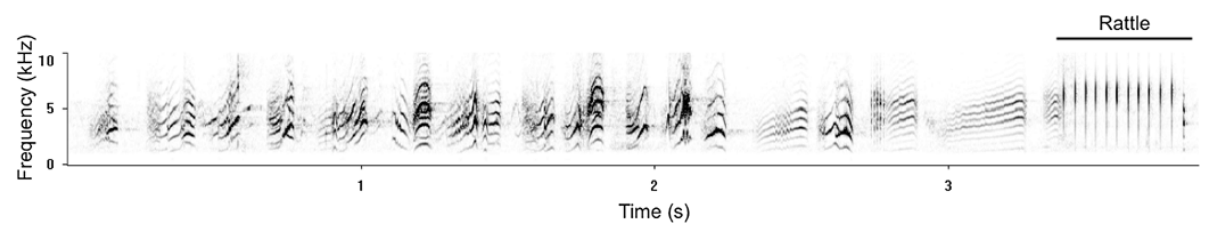

Figure 4 Example song spectrogram from $\boldsymbol{H}$. $\boldsymbol{r}$. rustica. Note 'rattle' component at terminal end of song and the large variety of complex syllables. Song spectrogram courtesy of M. Wilkins.

songs; additionally, males with longer rattles had higher levels of circulating testosterone, and these song features may therefore be involved in competitive interactions (Galeotti et al. 1997). Further, experiments showed that males with artificially elongated tails produced longer rattles (Saino et al. 2003), and immune challenged males reduced the lengths of their rattles (Dreiss et al. 2008), indicating that this trait is somewhat plastic and can respond to social and physiological cues. Longer rattles and longer tails are both linked to higher levels of circulating testosterone (Saino and Møller 1994; Galeotti et al. 1997, respectively), suggesting that a hormone-mediated social feedback loop similar to the one demonstrated with color in North American birds (Safran et al. 2008; Vitousek et al. 2013) may exist for song as well.

There is also some evidence that females consider song in mating decisions. Males with both long tails and higher song rates had fewer extra pair young in their nests (Møller et al. 1998b); however, the effect of tail was much more important in this relationship, indicating that shorttailed males cannot compensate for their unattractiveness by singing at higher rates. Additionally, males that sang overall longer songs paired more successfully and had lower ectoparasite loads (Garamszegi et al. 2005). Together, these data suggest that in European populations, some song components are used in territory defense and intrasexual competition, while other components may advertise condition and have a role in mate choice. Since clear links between tail streamer length and male-male competition have not been demonstrated in $H$. r. rustica (e.g. Saino and Møller 1995b), males may use different signaling modalities to communicate with potential mates vs. competitors.

Thus far there has been little research on song in nonEuropean Barn Swallow populations. However, recent work in North America found that some song features are important for male-male competition and while other components are used in female choice (Wilkins 2014), possibly implicating a greater role for song in mate choice in this short-streamered subspecies. Future comparative work on the information conveyed by song and melanin-based traits should further illuminate the costs and benefits associated with different types of signals across subspecies.

\section{From geographic variation in sexual selection to speciation}

It is clear that many traits, at least some of which are sexually selected, vary among the different Barn Swallow subspecies. But what causes geographic variation in phenotype? And what are the consequences of this variation for population divergence and speciation? Answering these questions entails examining the roles of selective and non-selective processes in shaping phenotypic variation and patterns of reproductive isolation. New species form when individuals from different populations no longer recognize one another as potential mates, or opportunities for mating become limited by differences in habitat use or reproductive schedules (Mayr 1942). In these cases, individuals are reproductively isolated and thus do not exchange genes; this is the first step towards speciation. Work in the field of speciation frequently focuses on identifying the processes that create barriers to gene flow among divergent populations. In this section we discuss the potential roles of natural selection, sexual selection, and drift in forming these barriers and driving phenotypic and population divergence in the Barn Swallow complex.

Speciation by natural selection, or "ecological speciation", occurs when populations living in different environments undergo adaptive evolutionary change via divergent natural selection. This process can form barriers to gene flow when divergent selection results in individuals being physically isolated from each other (i.e., in different ecological niches) or on different reproductive schedules (reviewed in Nosil 2012). Ecological speciation can often be inferred if ecologically divergent pairs of populations exhibit greater reproductive isolation than ecologically similar pairs of populations of similar age (e.g. Funk et al. 2006). Moreover, in cases of ecological speciation, the traits involved in divergent ecological adaptation should also contribute to reproductive isolation, and levels of gene flow in nature should decrease as ecological differences between populations increase (Nosil 2012).

Reproductive isolation can also emerge via divergent sexual selection (Panhuis et al. 2001; Ritchie 2007). In this scenario, divergence in traits related to reproductive success contributes to barriers to gene flow among populations. If reproductive isolation is caused by divergent sexual selection, pairs of populations might be expected 
to be ecologically similar but possess divergent mating traits (Panhuis et al. 2001).

Controversy has surrounded the role of sexual selection in speciation, particularly with respect to its relationship with divergent natural selection. At the center of this discussion is whether sexual selection alone can drive speciation, or whether ecological divergence is a prerequisite for the completion of reproductive isolation (Panhuis et al. 2001; Bussière et al. 2007; Safran et al. 2013). Although there are some cases in which sexual or natural selection is the dominant process driving divergence (reviewed in (Kraaijeveld et al. 2011)), the most common scenario is that sexual and natural selection act together to drive variation in the traits used in reproductive isolation (Safran et al. 2013; Scordato et al. 2014). The pertinent question then becomes not which process is most important in causing speciation, but how the two processes interact, how the phenotypic traits used in mate selection and reproductive isolation are shaped by this interaction, and if interactions are consistent or predictable across systems (Arnegard et al. 2010; Wagner et al. 2012; Safran et al. 2013).

Finally, some models of speciation do not include selection as a driver of divergence and reproductive isolation, but rather invoke a key role for chance events. These cases include speciation by genetic drift and founder-events/ population bottlenecks. Although such models have a long history in speciation research, for example in the context of small populations colonizing islands, clear empirical support is relatively limited (reviewed in Coyne and Orr 2004). However, when examining the causes of divergence and reproductive isolation among populations, adaptive divergence via selection cannot be assumed, and ruling out a role for random processes is critical.

\section{Divergent ecological and sexual selection in Barn Swallows}

Because the Barn Swallow complex has been the subject of extensive sexual selection research for decades and has several phenotypically variable subspecies that are tractable subjects for field studies, it is an ideal system in which to investigate the relative roles of ecological selection, sexual selection, and random processes in population divergence.

Several ecological variables could contribute to population and phenotypic divergence in Barn Swallows. There is variation in migratory distance among subspecies: some subspecies embark on migrations of many thousands of miles (i.e. European and North American populations), where as others are short-distance migrants or entirely sedentary (Middle Eastern populations; Møller 1994a; Turner 2006). Variation in migratory distance can exert natural selection on morphological factors like body size (Alerstam et al. 2003) and the shape of the wings (Mönkkönen 1995; Lockwood et al. 1998). Moreover, different wintering grounds and migratory routes can result in variation in the length and timing of the breeding season: birds that migrate longer distances typically have shorter and more synchronous breeding seasons than short-distance migrants (Garamszegi et al. 2008), which can translate into variation in selection on life history traits such as clutch size and incubation time, as well as mating strategies and parental care. Divergence in any of these traits could contribute to reproductive barriers, particularly if hybrids are unfit; for example, there is some evidence that the hybrid offspring of populations with different migratory pathways follow intermediate and maladaptive migration routes (Irwin 2009).

Geographic variation in sexual selection pressures may also drive phenotypic divergence and generate reproductive barriers in Barn Swallows. As we have discussed in this review, decades of work on the different sexually selected traits in this species show that the relative roles of streamer length, coloration, and possibly song in mate choice and male-male competition vary among subspecies. Even among European populations there is variation the strength of selection on tail length, although it remains consistently positive among populations (Møller et al. 2006). Likewise, the information conveyed by these traits varies geographically, with some evidence suggesting that long tail streamers in Europe advertise indirect benefits (Møller 1994a; Møller et al. 1998a); but see (Bro-Jørgensen et al. 2007) for alternative explanations), whereas coloration has been suggested to advertise direct and indirect benefits in Japan(Kojima et al. 2009; Hasegawa et al. 2012), and could relate to both direct and indirect benefits in North America (Safran and McGraw 2004; Safran et al. 2005). If the relative importance of different types of benefits varies among populations, this may result in mate choice, and consequent directional selection, on different traits, leading to phenotypic divergence and reproductive isolation based on sexually selected signals.

There is some evidence that sexually selected traits act as reproductive barriers in Barn Swallows: in an Israeli population of $H$. $r$. transitiva, males with color and tail length manipulated to look like the geographically proximate H. r. savignii were not attractive to females, suggesting there may be some selection against heterotypic matings in this populations (Vortman et al. 2013). These reproductive barriers are not complete, however: there is evidence for hybridization between H. r. rustica and $H$. $r$. tytleri in central Siberia, between H. r. tytleri and $H . r$. gutturalis in eastern Siberia (Turner 2006), and between H. r. rustica and H. r. transitiva in Israel (Dor et al. 2012), despite morphological differences between all these subspecies. Hybridization, if substantial, has the potential to reverse incipient differences among Barn Swallow subspecies. For example, it has been suggested that formerly geographically isolated subspecies in Asia may have been 
brought into contact by recent human settlement (Turner 2006). If reproductive barriers are porous, there may be an eventual loss of differentiation between subspecies, resulting in a uniform hybrid swarm.

To understand the action of ecological and sexual selection and their relative roles in generating (or breaking down) reproductive barriers, we ultimately need to study the substrates on which selection acts; that is, sexually and naturally selected traits and, in the case of sexual selection, their associated preferences. Future work explicitly measuring natural and sexual selection on different aspects of the phenotype will continue to shed light on how these processes operate in the Barn Swallow system. New techniques for obtaining genome-wide estimates of selection are greatly advancing our ability to study the loci involved in reproductive isolation and identify signatures of divergence via adaptation versus random processes.

\section{Conclusions and future directions}

Here we have reviewed sexual selection research in Barn Swallows dating back nearly 30 years. Although this vast body of work has made Barn Swallows a model system in evolutionary biology, recent comparative studies show that much remains to be discovered in this species complex. Future comparative research addressing the relative roles of tail streamers, plumage coloration, and song in mating decisions across the different subspecies, as well as determining the information conveyed by these different signals, would help illuminate why the targets of female preferences appear to vary geographically. This work would be enhanced by ecological studies that focus on how different mating traits are shaped by natural selection as well as sexual selection, and by carefully designed experiments that can test the relative contributions of different selective processes to variation within and among subspecies. Finally, advances in genomic methods for detecting ongoing gene flow and the genetic basis of reproductive isolation present the possibility of studying reproductive barriers and causes of diversification among the different subspecies. Integrations of experimental, geographic, ecological, and genomic approaches are likely to yield new insight into sexual selection and speciation in the Barn Swallow complex over the coming decades.

\section{Competing interests}

The authors declare that they have no competing interests.

\section{Authors' contributions}

ESCS and RJS devised and wrote the manuscript. All authors read and approved the final version of this manuscript.

\section{Acknowledgments}

We thank W. Liang for the invitation to write this review, and A. Hund and $M$. Wilkins for comments on the manuscript. Support was provided by the National Science Foundation (DEB-CAREER 1149942 to RJS).
Received: 26 November 2014 Accepted: 27 November 2014

Published online: 24 December 2014

\section{References}

Alerstam T, Hedenström A, Åkesson S (2003) Long-distance migration: evolution and determinants. Oikos 103:247-260

Andersson MB (1994) Sexual Selection. Princeton University Press, Princeton

Aparicio JM, Møller AP (2012) Artefactual effects of tail manipulation on fitness. Anim Behav 83:e1-e3

Arnegard ME, McIntyre PB, Harmon LJ, Zelditch ML, Crampton WGR, Davis JK, Sullivan JP, Lavoué S, Hopkins CD (2010) Sexual signal evolution outpaces ecological divergence during electric fish species radiation. Am Nat 176:335-356

Bro-Jørgensen J, Johnstone RA, Evans MR (2007) Uninformative exaggeration of male sexual ornaments in barn swallows. Curr Biol 17:850-855

Buchanan KL, Evans MR (2000) The effect of tail streamer length on aerodynamic performance in the barn swallow. Behav Ecol 11:228-238

Bussière LF, Hunt J, Asplen MK, Jennions MD, Brooks R (2007) Mate choice for genetic quality when environments vary: suggestions for empirical progress. Genetica 134:69-78

Coyne JA, Orr HA (2004) Speciation. Sinauer Associates Sunderland, MA

Cuervo JJ, de Lope F, Møiller AP (1996a) The function of long tails in female barn swallows (Hirundo rustica): an experimental study. Behav Ecol 7:132-136

Cuervo JJ, de Lope F, Møller AP, Moreno J (1996b) Energetic cost of tail streamers in the barn swallow (Hirundo rustica). Oecologia 108:252-258

Darwin C (1871) The Descent of Man and Selection in Relation to Sex. John Murray, London

De Lope F, Møller AP (1993) Female reproductive effort depends on the degree of ornamentation of their mates. Evolution 47:152-1160

Del Hoyo J, Elliott A (2014) Barn Swallow (Hirundo rustica). In: Handbook of the Birds of the World: Alive. Lynx Edicions, Spain.

Dor R, Safran RJ, Sheldon FH, Winkler DW, Lovette IJ (2010) Phylogeny of the genus Hirundo and the Barn Swallow subspecies complex. Mol Phylogenet Evol 56:409-418

Dor R, Safran RJ, Vortman Y, Lotem A, McGowan A, Evans MR, Lovette IJ (2012) Population genetics and morphological comparisons of migratory European (Hirundo rustica rustica) and sedentary East-Mediterranean (Hirundo rustica transitiva) barn swallows. J Hered 103:55-63

Dreiss AN, Navarro C, De Lope F, Møller AP (2008) Effects of an immune challenge on multiple components of song display in barn swallows Hirundo rustica: implications for sexual selection. Ethology 114:955-964

Ducrest AL, Keller L, Roulin A (2008) Pleiotropy in the melanocortin system, coloration and behavioural syndromes. Trends Ecol Evol 23:502-510

Eikenaar C, Whitham M, Komdeur J, Van der Velde M (2011a) Testosterone, plumage colouration and extra-pair paternity in male North-American barn swallows. PLoS ONE 6:e23288

Eikenaar C, Whitham M, Komdeur J, Van der Velde M (2011b) Endogenous testosterone is not associated with the trade-off between paternal and mating effort. Behav Ecol 22:601-608

Evans MR (1998) Selection on swallow tail streamers. Nature 394:233-234

Evans MR (1999) Reply: length of tail streamers in barn swallows. Nature 397:115-116

Evans MR (2004) Limits on the evolution of tail ornamentation in birds. Am Nat 163:341-358

Evans MR, Thomas A (1997) Testing the functional significance of tail streamers. Proc R Soc Lond B Biol Sci 264:211-217

Evans MR, Bro-Jørgensen J, Johnstone RA (2012) Tail manipulations affect fitness traits in male barn swallows. Anim Behav 83:e4-e5

Funk DJ, Nosil P, Etges WJ (2006) Ecological divergence exhibits consistently positive associations with reproductive isolation across disparate taxa. PNAS 103:3209-3213

Galeotti P, Saino N, Sacchi R, Møller AP (1997) Song correlates with social context, testosterone and body condition in male barn swallows. Anim Behav 53:687-700

Galván I, Alonso-Alvarez C (2008) An intracellular antioxidant determines the expression of a melanin-based signal in a bird. PLoS ONE 3:e3335

Galván I, Alonso-Alvarez C (2009) The expression of melanin-based plumage is separately modulated by exogenous oxidative stress and a melanocortin. Proc R Soc Lond B Biol Sci 276:3089-3097

Galván I, Møller AP (2013) Pheomelanin-based plumage coloration predicts survival rates in birds. Physiol Biochem Zool 86:184-192 
Garamszegi LZ, Heylen D, Møller AP, Eens M, De Lope F (2005) Age-dependent health status and song characteristics in the barn swallow. Behav Ecol 16:580-591

Garamszegi LZ, Hirschenhauser K, Bókony V, Eens M, Hurtrez-Boussès S, Møller AP, Oliveira RF, Wingfield JC (2008) Latitudinal distribution, migration, and testosterone levels in birds. Am Nat 172:533-546

Grafen A (1990) Biological signals as handicaps. J Theoret Biol 144:517-546

Hasegawa M, Arai E (2013a) Divergent tail and throat ornamentation in the barn swallow across the Japanese islands. J Ethol 31:79-83

Hasegawa M, Arai E (2013b) Differential female access to males with large throat patches in the Asian barn swallow Hirundo rustica gutturalis. Zool Sci 30:913-918

Hasegawa M, Arai E, Watanabe M, Nakamura M (2010) Mating advantage of multiple male ornaments in the Barn Swallow Hirundo rustica gutturalis. Ornithol Sci 9:141-148

Hasegawa M, Arai E, Watanabe M, Nakamura M (2012) Female mate choice based on territory quality in barn swallows. J Ethol 30:143-150

Hasegawa M, Arai E, Watanabe M, Nakamura M (2013) Male viability is positively related to multiple male ornaments in Asian Barn Swallows. J Ornith 155:1-9

Hasegawa M, Arai E, Watanabe M, Nakamura M (2014) Colourful males hold high quality territories but exhibit reduced paternal care in barn swallows. Behaviour 151:591-612

Hedenström A, Møller AP (1999) Length of tail streamers in barn swallows. Nature 397:115-115

Hill GE, McGraw KJ (2006) Bird Coloration: Function and Evolution. Harvard University Press, Cambridge, MA

Hubbard JK, Uy JAC, Hauber ME, Hoekstra HE, Safran RJ (2010) Vertebrate pigmentation: from underlying genes to adaptive function. Trends Genet 26:231-239

Irwin DE (2009) Speciation: new migratory direction provides route toward divergence. Curr Biol 19:R1111-R1113

Iwasa Y, Pomiankowski A, Nee S (1991) The evolution of costly mate preferences II. The "handicap" principle. Evolution 45:1431-1442

Jenkins BR, Vitousek MN, Safran RJ (2013) Signaling stress? An analysis of phaeomelanin-based plumage color and individual corticosterone levels at two temporal scales in North American barn swallows, Hirundo rustica erythrogaster. Horm Behav 64:665-672

Jiggins CD, Estrada C, Rodrigues A (2004) Mimicry and the evolution of premating isolation in Heliconius melpomene Linnaeus. J Evol Biol 17:680-691

Ketterson ED, Nolan V Jr, Wolf L, Ziegenfus C (1992) Testosterone and avian life histories: effects of experimentally elevated testosterone on behavior and correlates of fitness in the dark-eyed junco (Junco hyemalis). Am Nat 140:980-999

Kirkpatrick M (1996) Good genes and direct selection in the evolution of mating preferences. Evolution 50:2125-2140

Kleven O, Jacobsen F, Izadnegahdar R, Robertson RJ, Lifjeld JT (2006) Male tail streamer length predicts fertilization success in the North American barn swallow (Hirundo rustica erythrogaster). Behav Ecol Sociobiol 59:412-418

Kojima W, Kitamura W, Kitajima S, Ito Y, Ueda K, Fujita G, Higuchi H (2009) Female barn swallows gain indirect but not direct benefits through social mate choice. Ethology 115:939-947

Kose M, Møller AP (1999) Sexual selection, feather breakage and parasites: the importance of white spots in the tail of the barn swallow (Hirundo rustica). Behav Ecol Sociobiol 45:430-436

Kose M, Mänd R, Møller AP (1999) Sexual selection for white tail spots in the barn swallow in relation to habitat choice by feather lice. Anim Behav 58:1201-1205

Kraaijeveld K, Kraaijeveld-Smit FJ, Maan ME (2011) Sexual selection and speciation: the comparative evidence revisited. Biol Rev 86:367-377

Lifjeld JT, Kleven O, Jacobsen F, McGraw KJ, Safran RJ, Robertson RJ (2011) Age before beauty? Relationships between fertilization success and age-dependent ornaments in barn swallows. Behav Ecol Sociobiol 65:1687-1697

Lockwood R, Swaddle JP, Rayner JM (1998) Avian wingtip shape reconsidered: wingtip shape indices and morphological adaptations to migration. J Avian Biol 29:273-292

Maan ME, Cummings ME (2008) Female preferences for aposematic signal components in a polymorphic poison frog. Evolution 62:2334-2345

Maguire SE, Safran RJ (2010) Morphological and genetic predictors of parental care in the North American barn swallow Hirundo rustica erythrogaster. J Avian Biol 41:74-82

Martínez MM (1983) Nidificación de Hirundo rustica erythrogaster (Boddaert) en la Argentina (Aves, Hirundinidae). Neotropica 29:83-86
Mayr E (1942) Systematics and the Origin of Species, from the Viewpoint of a Zoologist. Harvard University Press, Cambridge

McGraw KJ, Saran RJ, Wakamatsu K (2005) How feather colour reflects its melanin content. Function Ecol 19:816-821

Møller AP (1988) Female choice selects for male sexual tail ornaments in the monogamous swallow. Nature 332:640-642

Møller AP (1989) Viability costs of male tail ornaments in a swallow. Nature 339:132-135

Møller AP (1990) Male tail length and female mate choice in the monogamous swallow Hirundo rustica. Anim Behav 39:458-465

Møller AP (1991a) Viability is positively related to degree of ornamentation in male swallows. Proc R Soc Lond B Biol Sci 243:145-148

Møller AP (1991 b) Preferred males acquire mates of higher phenotypic quality. Proc R Soc Lond B Biol Sci 245:179-182

Møller AP (1994a) Sexual Selection and the Barn Swallow. Oxford University Press, Oxford

Møller AP (1994b) Male ornament size as a reliable cue to enhanced offspring viability in the barn swallow. PNAS 91:6929-6932

Møller AP (1995) Sexual selection in the barn swallow (Hirundo rustica).V Geographic variation in ornament size J Evol Biol 8:3-19

Møller AP, de Lope F (1994) Differential costs of a secondary sexual character: an experimental test of the handicap principle. Evolution 48:1676-1683

Møller AP, Szép T (2002) Survival rate of adult barn swallows Hirundo rustica in relation to sexual selection and reproduction. Ecology 83:2220-2228

Møller AP, Tegelström H (1997) Extra-pair paternity and tail ornamentation in the barn swallow Hirundo rustica. Behav Ecol Sociobiol 41:353-360

Møller AP, de Lope F, Caballero JL (1995) Foraging costs of a tail ornament: experimental evidence from two populations of barn swallows Hirundo rustica with different degrees of sexual size dimorphism. Behav Ecol Sociobiol 37:289-295

Møller AP, Barbosa A, Cuervo JJ, de Lope F, Merino S, Saino N (1998a) Sexual selection and tail streamers in the barn swallow. Proc R Soc Lond B Biol Sci 265:409-414

Møller AP, Saino N, Taramino G, Ferrario S, Galeotti P (1998b) Paternity and multiple signaling: effects of a secondary sexual character and song on paternity in the barn swallow. Am Nat 151:236-242

Møller AP, Brohede J, Cuervo JJ, de Lope F, Primmer C (2003) Extrapair paternity in relation to sexual ornamentation, arrival date, and condition in a migratory bird. Behav Ecol 14:707-712

Møller AP, Martinelli R, Saino N (2004) Genetic variation in infestation with a directly transmitted ectoparasite. J Evol Biol 17:41-47

Møller AP, Chabi Y, Cuervo JJ, Lope F, Kilpimaa J (2006) An analysis of continent-wide patterns of sexual selection in a passerine bird. Evolution 60:856-868

Mönkkönen M (1995) Do migrant birds have more pointed wings?: a comparative study. Evol Ecol 9:520-528

Neuman CR, Safran RJ, Lovette IJ (2007) Male tail streamer length does not predict apparent or genetic reproductive success in North American barn swallows Hirundo rustica erythrogaster. J Avian Biol 38:28-36

Ninni P, de Lope F, Saino N, Haussy C, Møller AP (2004) Antioxidants and condition - dependence of arrival date in a migratory passerine. Oikos 105:55-64

Nosil P (2012) Ecological Speciation. Oxford University Press, Oxford

Panhuis TM, Butlin R, Zuk M, Tregenza T (2001) Sexual selection and speciation. Trends Ecol Evol 16:364-371

Price T (2008) Speciation in Birds. Roberts, Boulder, Colorado

Price T, Schluter D, Heckman NE (1993) Sexual selection when the female directly benefits. Biol J Linnean Soc 48:187-211

Ritchie MG (2007) Sexual selection and speciation. Ann Rev Ecol Evol System 38:79-102

Roulin A, Almasi B, Rossi-Pedruzzi A, Ducrest A-L, Wakamatsu K, Miksik I, Blount JD, Jenni-Eiermann S, Jenni L (2008) Corticosterone mediates the condition-dependent component of melanin-based coloration. Anim Behav 75:1351-1358

Rowe LV, Evans MR, Buchanan KL (2001) The function and evolution of the tail streamer in hirundines. Behav Ecol 12:157-163

Safran RJ, McGraw KJ (2004) Plumage coloration, not length or symmetry of tail-streamers, is a sexually selected trait in North American barn swallows. Behav Ecol 15:455-461

Safran RJ, Neuman CR, McGraw KJ, Lovette IJ (2005) Dynamic paternity allocation as a function of male plumage color in barn swallows. Science 309:2210-2212

Safran RJ, Adelman JS, McGraw KJ, Hau M (2008) Sexual signal exaggeration affects physiological state in male barn swallows. Curr Biol 18:R461-R462 
Safran RJ, Scordato ES, Symes LB, Rodríguez RL, Mendelson TC (2013) Contributions of natural and sexual selection to the evolution of premating reproductive isolation: a research agenda. Trends Ecol Evol 28:643-650

Saino N, Møller AP (1994) Secondary sexual characters, parasites and testosterone in the barn swallow, Hirundo rustica. Anim Behav 48:1325-1333

Saino N, Møller AP (1995a) Testosterone-induced depression of male parental behavior in the barn swallow: female compensation and effects on seasonal fitness. Behav Ecol Sociobiol 36:151-157

Saino N, Møller AP (1995b) Testosterone correlates of mate guarding, singing and aggressive behaviour in male barn swallows, Hirundo rustica. Anim Behav 49:465-472

Saino N, Møller AP (1996) Sexual ornamentation and immunocompetence in the barn swallow. Behav Ecol 7:227-232

Saino N, Bolzern AM, Møller AP (1997a) Immunocompetence, ornamentation, and viability of male barn swallows (Hirundo rustica). PNAS 94:549-552

Saino N, Primmer CR, Ellegren H, Møller AP (1997b) An experimental study of paternity and tail ornamentation in the barn swallow (Hirundo rustica). Evolution 51:562-570

Saino N, Incagli M, Martinelli R, Møller AP (2002) Immune response of male barn swallows in relation to parental effort, corticosterone plasma levels, and sexual ornamentation. Behav Ecol 13:169-174

Saino N, Romano M, Sacchi R, Ninni P, Galeotti P, Møller AP (2003) Do male barn swallows (Hirundo rustica) experience a trade-off between the expression of multiple sexual signals? Behav Ecol Sociobiol 54:465-471

Saino N, Canova L, Costanzo A, Rubolini D, Roulin A, Møller AP (2013a) Immune and stress responses covary with melanin-based coloration in the barn swallow. Evol Biol 40:521-531

Saino N, Romano M, Rubolini D, Ambrosini R, Caprioli M, Milzani A, Costanzo A, Colombo G, Canova L, Wakamatsu K (2013b) Viability is associated with melanin-based coloration in the barn swallow (Hirundo rustica). PLOS ONE 8:e60426

Saino N, Romano M, Rubolini D, Teplitsky C, Ambrosini R, Caprioli M, Canova L, Wakamatsu K (2013c) Sexual dimorphism in melanin pigmentation, feather coloration and its heritability in the barn swallow (Hirundo rustica). PLOS ONE 8:e58024

Scordato ESC, Symes LB, Mendelson TC, Safran RJ (2014) The Role of Ecology in Speciation by Sexual Selection: A Systematic Empirical Review. J Hered 105:782-794

Smith HG, Montgomerie R (1991) Sexual selection and the tail ornaments of North American barn swallows. Behav Ecol Sociobiol 28:195-201

Smith HG, Montgomerie R, Pōldman T, White BN, Boag PT (1991) DNA fingerprinting reveals relation between tail ornaments and cuckoldry in barn swallows, Hirundo rustica. Behav Ecol 2:90-98

Turner A (2006) The Barn Swallow. T\&AD Poyser, London

Vitousek MN, Stewart RA, Safran RJ (2013) Female plumage colour influences seasonal oxidative damage and testosterone profiles in a songbird. Biol Let 9:20130539

Vortman Y, Lotem A, Dor R, Lovette IJ, Safran RJ (2011) The sexual signals of the East-Mediterranean barn swallow: a different swallow tale. Behav Ecol 22:1344-1352

Vortman Y, Lotem A, Dor R, Lovette I, Safran RJ (2013) Multiple sexual signals and behavioral reproductive isolation in a diverging population. Am Nat 182:514-523

Wagner CE, Harmon L, Seehausen O (2012) Ecological opportunity and sexual selection together predict adaptive radiation. Nature 487:366-369

Wilkins MR (2014) Evolutionary divergence in sexual signals: insights from within and among barn swallow populations. PhD Thesis. The University of Colorado.

Zahavi A (1975) Mate selection — a selection for a handicap. J Theor Biol 53:205-214

Zink RM, Pavlova A, Rohwer S, Drovetski SV (2006) Barn swallows before barns: population histories and intercontinental colonization. Proc R Soc B Biol Sci 273:1245-1251

\section{Submit your next manuscript to BioMed Central and take full advantage of:}

- Convenient online submission

- Thorough peer review

- No space constraints or color figure charges

- Immediate publication on acceptance

- Inclusion in PubMed, CAS, Scopus and Google Scholar

- Research which is freely available for redistribution 